\title{
Developing a mobile visualization environment for construction applications
}

Conference or Workshop Item

Published Version

Conference Paper

Mallia-Parfitt, M. and Whyte, J. (2014) Developing a mobile visualization environment for construction applications. In: Proceedings of the 2014 International conference on Computing in Civil and Building Engineering, 23-25 June 2014, Orlando, Florida, pp. 825-832. Available at http://centaur.reading.ac.uk/37543/

It is advisable to refer to the publisher's version if you intend to cite from the work. See Guidance on citing.

Published version at: http://128.227.160.197/icccbe2014/schedule/

All outputs in CentAUR are protected by Intellectual Property Rights law, including copyright law. Copyright and IPR is retained by the creators or other copyright holders. Terms and conditions for use of this material are defined in the End User Agreement. 


\section{www.reading.ac.uk/centaur}

\section{CentAUR}

Central Archive at the University of Reading

Reading's research outputs online 


\title{
Developing a Mobile Visualization Environment for Construction Applications
}

\author{
Maxwell Parfitt, Ph.D. ${ }^{1}$ and Jennifer Whyte, Ph.D. ${ }^{2}$
}

Design Innovation Research Centre, School of Construction Management and Engineering, University of Reading, UK;

Email: ${ }^{1}$ m.r.parfitt@ reading.ac.uk, ${ }^{2}$ j.whyte@ reading.ac.uk

\begin{abstract}
There is a renewed interest in immersive visualization to navigate digital data-sets associated with large building and infrastructure projects. Following work with a fully immersive visualization facility at the University, this paper details the development of a complementary mobile visualization environment. It articulates progress on the requirements for this facility; the overall design of hardware and software; and the laboratory testing and planning for user pilots in construction applications. Like our fixed facility, this new light-weight mobile solution enables a group of users to navigate a 3D model at a 1:1 scale and to work collaboratively with structured asset information. However it offers greater flexibility as two users can assemble and start using it at a new location within an hour. The solution has been developed and tested in a laboratory and will be piloted in engineering design review and stakeholder engagement applications on a major construction project.
\end{abstract}

KEYWORDS: mobile, immersive display, BIM, visualization, virtual reality.

\section{INTRODUCTION}

Building Information Modelling (BIM) is becoming used in delivery of large building and infrastructure projects (Eastman, Teicholz et al. 2008). As structured asset information is collated, data-sets may involve many thousands and in some cases millions of items (Stasis, Whyte et al. 2012; Lindkvist, Stasis et al. 2013). There is a renewed interest in immersive visualization to navigate and understand such large data-sets.

Recently a number of researchers have started to revisit and further explore the use of immersive visualization as a means to engage with building information modelling data-sets from a number of perspectives (Maftei and Harty 2012; Castronovo, Nikolic et al. 2013; Kim, Wang et al. 2013; Sacks, Perlma et al. 2013). This draws on a significant history of using immersive visualization facilities in construction (Bertol 1997; Whyte 2002; Bouchlaghem, Shang et al. 2005), with architecture and built environment applications motivating early developments of virtual reality (e.g. Brooks 1986). The CAVE virtual reality system involves projection onto multiple screens that surround a viewer (Cruz-Neira, Sandin et al. 
1992; Cruz-Neira, Sandin et al. 1993). However, implementation is limited to installations in purpose adapted rooms, with sizeable areas required to house large mirrors to project images onto the screens (Figure 1.a). The projection equipment and projection angles take substantial time to calibrate, such that utilizing existing technology for a portable solution would be unfeasible.

This paper explores the design of a fully-immersive visualization prototype (Figure 1.b), which uses ultra-short throw projectors without the need for extensive set-up time. The solution was developed following collaboration with industrial partners that raised the question: 'What would it take to bring immersive visualization into our offices?' The next sections describe the research design, the requirements and considerations; design of the mobile visualization environment; and then testing and piloting. The paper concludes by summarizing the work to date, and giving a description of future work in visualization streamlining and solution testing through piloting for engineering design review and stakeholder engagement with a major construction project.

\section{RESEARCH DESIGN}

The immersive visualization facility at the University of Reading is used extensively in research with industry partners for the immersive 3D display of digital data from their complex projects, and for virtual mock-up applications (Figure 1.a). It has recently been upgraded, to run under Windows, using MiddleVR and Unity, with significant work on workflows from standard industry packages (Dalton and Parfitt 2013) to reduce time from model delivery to immersive visualization.

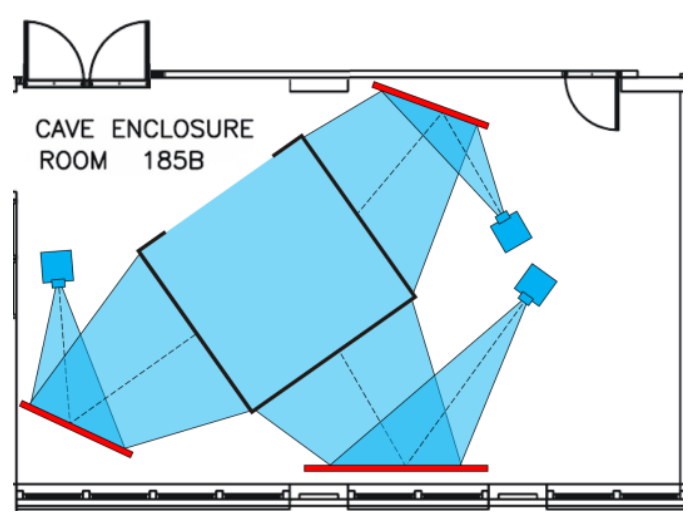

a) University of Reading immersive visualization facility floor plan

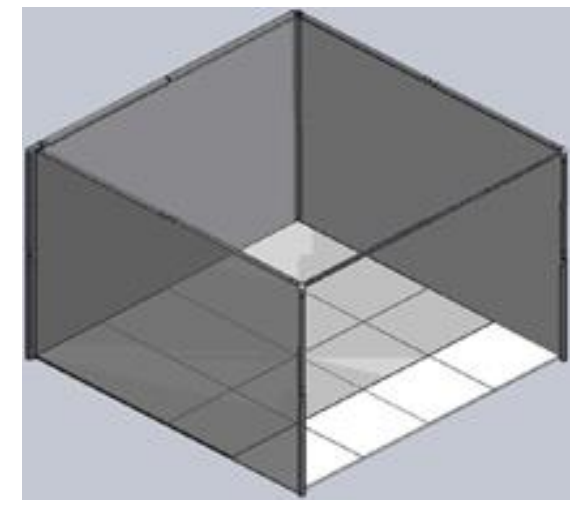

b) Prototype Design - Concept manufactured ready for user testing

Figure 1. The immersive facility at the University (a) the prototype design using the same internal layout (b).

Learning from this upgrade process has informed the development of the mobile immersive facility with the same internal layout (Figure 1.b). This is engineering research with three main steps:

1. Requirements - working with industry partners in our immersive facility and understanding their needs. This involved four meetings with our collaborators in 
Whitechapel station and other parts of the Crossrail project, three of which were held on the University campus around the facilities, and the other was to visit a solution that was in use on a current station project;

2. Design of a mobile immersive facility - involving the identification and evaluation of technical options, such as the choice of hardware (material, 3D printing, screen and floor design), and software (for real-time viewing and multiple screen rendering); the manufacturing of the prototype and adjustments required; and

3. Testing and user pilots - laboratory tests and work with industry partners to pilot the use of the mobile immersive visualization environment for two construction applications: engineering design review and stakeholder engagement. We are about to start the user testing phase of the research working with Crossrail.

\section{REQUIREMENTS AND CONSIDERATIONS}

Following our initial meeting with industrial partners from a construction project, we obtained model data that we used in developing workflows to visualize asset information immersively. The second meeting was used to demonstrate these immersive capabilities, and to discuss the requirements for a mobile alternative.

Through our conversations with these industry partners, and a range of software and hardware suppliers, we set out requirements for the mobile visualization environment to be:

1. real-time stereoscopic visualization at a 1:1 scale to enable designers and engineers to work collaboratively with structured asset information, as they did in the fixed facility;

2. freestanding while supporting a minimum of three screens (three walls) and their associated projectors; and

3. portable so that two people with access to a small van can quickly assemble the mobile facility, making it usable within an hour of arriving on site.

This requires simple alignment of projectors as the current fixed facility calibration processes take nearly 2 hours per screen. The mechanical framework requirements, Table 1, were considered to ensure the frame design will support the screens while not collapsing under its own weight.

Table 1. Requirements for framework design

\begin{tabular}{|l|l|}
\hline \multicolumn{1}{|c|}{ Requirement } & \multicolumn{1}{|c|}{ Importance to success } \\
\hline $\begin{array}{l}\text { Lightweight enough to be } \\
\text { transported by two people without } \\
\text { risking injury. }\end{array}$ & $\begin{array}{l}\text { Extremely High: Total solution should not weigh } \\
\text { more than 100 Kg to aid with manual handling. }\end{array}$ \\
\hline $\begin{array}{l}\text { When assembled, must support the } \\
\text { weight of the screen material, } \\
\text { projectors, speakers, cables, etc. }\end{array}$ & $\begin{array}{l}\text { Extremely High: If the frame is not strong enough } \\
\text { it will pose a fall hazard to users both during } \\
\text { assembly and use. }\end{array}$ \\
\hline Durable enough to withstand & High: If parts wear out they can be replaced, but \\
\hline
\end{tabular}




\begin{tabular}{|l|l|}
\hline repeated disassembly. & this should not happen too often. \\
\hline $\begin{array}{l}\text { Cost effective solution compared } \\
\text { to commercial solutions. }\end{array}$ & $\begin{array}{l}\text { Medium: As a prototype this will keep a limit to } \\
\text { costs whilst providing exact specifications. }\end{array}$ \\
\hline $\begin{array}{l}\text { Pack or collapse down into } \\
\text { minimal space to aid with storage } \\
\text { and transport. }\end{array}$ & $\begin{array}{l}\text { Medium: The visualization prototype is intended } \\
\text { to only be packed away during transport, but if } \\
\text { necessary will fit into a small storage volume. }\end{array}$ \\
\hline $\begin{array}{l}\text { Utilise novel technologies such as } \\
\text { Additive Manufacturing and 3D } \\
\text { printing, to create specialised non- } \\
\text { commercial components. }\end{array}$ & $\begin{array}{l}\text { High: To ensure success of prototype and accuracy } \\
\text { of components, novel technologies will be } \\
\text { employed to manufacture components either not } \\
\text { available commercially or too expensive to } \\
\text { manufacture using traditional means. }\end{array}$ \\
\hline
\end{tabular}

\section{DESIGN OF THE FACILITY}

Hardware. The new mobile visualization environment uses modern composite materials and 3D printing techniques to construct a portable framework that tensions a screen fabric to create the flexible presentation space. This prototype has the same usable performance volume as existing fixed location facilities, $2.8 \mathrm{x}$ $2.8 \times 2.1$ meters, with the vertical leg supports creating the three walled environment with possible floor or roof projection (4 walled environment). Through the use of ultra-short throw projector technology, large mirrors used with the projection system to fold images onto the screens are no longer required so, the overall footprint of the system is reduced such that it can be used in a standard office environment.

1. Materials choice - The frame design has to be lightweight and simple to construct on arrival at a site. To evaluate different framework solutions with respects to Table 1, a comparison study was performed to take into consideration different material choices that could meet the requirement for a rigid but flexible framework that could support both the projection surfaces as well as projectors.

After experimentation and Finite Element Analysis (FEA) simulation, the material best suited for the frame construction was found to be Composite Carbon Fibre tube, due to its very light weight construction, extremely strong properties in compression, very low flex in deflection tests and relative cost. Whilst the Steel Extruded Box shared similar deflection, durability and cost to the Carbon Fibre Tube, the mass of the tubing would have made the frame too heavy to be portable, over $100 \mathrm{Kg}$ (Steel Extruded Box) compared to $7.36 \mathrm{Kg}$ (Carbon Fibre Tube) utilising a total of 19.5 meters of material length.

To increase portability and reduce the required size for transport, the tubing chosen for the design is telescopic, allowing the 19.5 meters of tube to collapse into four 1.4 meter lengths, making the frame very compact to store and can easily be carried by hand with a strap around the four tubes. The carbon fibre tube has different properties of deflection depending on tube diameter, so the larger tubes can be used to support greater masses whilst keeping deflection to a minimum, hence the largest diameter tube will support the floor projector on the rear span. 
2. Adoption of $3 D$ Additive Manufacture - The carbon fibre tube chosen for the frame poses problems for assembly due to the differing diameters, as no commercially available products can join the diameters selected; as such custom frame connectors were designed. The tube connectors have to sit flush with the tubes to not interfere or deform the screen material that is tensioned across joints, whilst being hollow to allow cables to run through and strong enough to support the loads expected under the frames use. Extruded Plastic Additive Manufacture was chosen due to the excessive cost, time and material wastage incurred through subtractive manufacturing processes, therefore components could be quickly and accurately realised, compared to outsourcing to subtractive manufacture. The cost and time of manufacture was also greatly reduced through the use of 3D printing compared to outsourced subtractive manufacture, as such, 3D printing of all components took only 84 hours.

The 3D printed components are robust enough to have additional subtractive manufacturing process performed after printing, such as having screw threads tapped, surface sanding and additional holes drilled. The frame's corner joints, through an integrated tensioning system, allow a user to adjust the screen tension to produce a 'ripple free' projection surface.

3. Screen design - The screen material choice is essential to the prototypes success, with many different design considerations required to ensure optimal viewing experience for the user and durability of the solution.

There was experimentation with flexible rear projection material for the design to ensure that optimal image quality from a range of projection and viewing angles as ultra-short throw projectors have a tendency to 'hot spot' a display, creating a brighter image towards the centre of the projectors focal axis. Material experimentation was performed between two products, chosen for their optical transmittance and gain properties.

An experiment to assess the optical properties of the two materials projected colour bars using an ultra-short throw projector onto two targets, which could then be photographed at varying viewing angles with a fixed focus camera. This experimentation created a way to directly compare the two material types visually, so that the best representation of colours and shades of black and white could be chosen across the various viewing angles a user might experience whilst using the immersive environment. The material chosen has vivid colour representation with less variance between viewing angles. Though the rejected material gives superior rejection of ambient light and crisp black representation, the rest of the colours are very dark requiring more powerful projectors.

The fabric screens require tensioning to ensure creases do not obstruct projected images and that air disturbances do not cause the image to wobble from displacement of the screen surface. The screens are pulled taught by the frame running though integrated pockets, much like a geodesic tents support structure, with additional vertical tensioning provided by a false floor. The screens tension is dependent on ambient temperature; the colder it is the more the material contracts. 
4. False Floor Design - To provide the required vertical tension for the screens, a false floor has been included in the design. The floor panels are fitted with Dual Lock (Bychinski, Lindseth et al. 1992; Messler 2000; Bandyopadhyay 2004), a resalable tape similar to hook and loop systems, which connects with Dual Lock located at the bottom of the screens audience side. The weight of the floor panels pull the screens vertically down, with additional tension achievable by changing the position of the Dual Lock bond.

The false floor needed to satisfy a number of requirements to ensure that it is suitable for use, such as; being simple to assemble on site, lightweight for portability, be able to fold or collapse in some manor to aid with transport and be strong enough to support foot traffic. To ensure that the false floor is lightweight the aerospace industry was approached for advice on the lightweight floor panels similar to those used in aircraft (Black 2006).

Each panel has a mass of $5.2 \mathrm{Kg}$ and measures 1.4 x 0.7 x 0.022 meters, with a recessed grove routed around the edges to fit the Dual Lock tape. When placed together the Dual Lock binds, holding the panels firmly in the correct location, doubling as an additional projection surface, even with heavy foot traffic.

Software. The same configuration of MiddleVR and Unity, which were used in upgrading the fixed immersive visualization facility and reducing workflows from standard industry packages (Dalton \& Parfitt, 2013), were also implemented in the mobile visualization environment. MiddleVR provides support for multiple displays and stereo-viewing across multiple displays. Unity is a gaming engine that enables models to be navigated in real-time.

\section{LABORATORY TESTS AND USER PILOTS}

The 3D printed components were subjected to deflection and impact testing to ensure no delamination or deformation before they were included in the frame assembly, which was tested through repeated assembly and disassembly cycles, with no apparent fracturing occurring in the joints or composite tubes.

To ensure the screen could be sufficiently tensioned, assembly and calibration was performed under a range of office temperatures, 10 to 30 degrees centigrade. The solution testing showed stable operation under simulated load and temperature conditions.

To ensure that time of assembly to operation adhered to requirements, the construction of the solution was timed on three occasions using different personnel. The fastest time recorded was 32 minutes with an average of 41 minutes for two users to assemble and calibrate the facility ready for use. To ensure calibration of the screens and user interface, non-technical users was asked to find visual defects in the immersive environment, (Figure 2), noting their experience and sense of immersion. The current prototype does not contain head-tracking, so users noticed a warped visual display if they stood significantly off the projection axis, but most users found their experience was not drastically affected. 


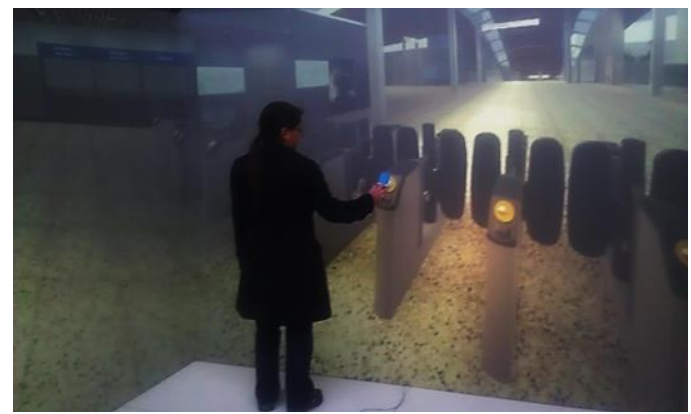

a) User testing visualization scale through simulated interaction

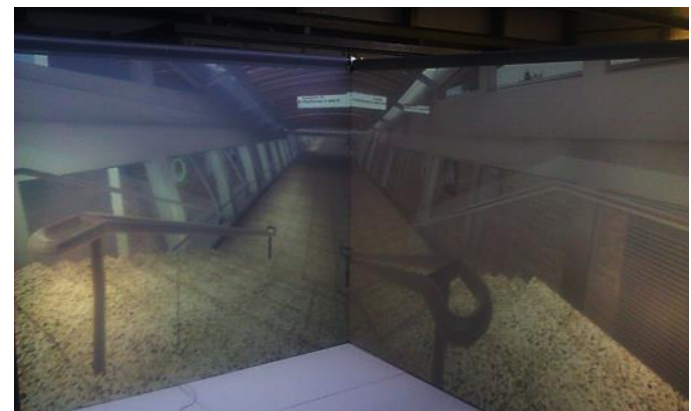

b) Navigation of concourse stairs using 3D Space Navigator Mouse

Figure 2. User inside the Whitechapel Station visualization showing both interaction (a) and navigation (b).

\section{CONCLUSIONS AND FUTURE WORK}

Work to date has seen the mobile visualization solution constructed and tested at the University under laboratory conditions, giving an immersive experience close to that of our existing static solution. The contribution is to provide a mobile version that enables BIM data to be rapidly visualized and displayed in locations that are close to construction activities. User testing for engineering design review and stakeholder engagement applications is about to commence on a major construction project. In this testing we plan to work with Crossrail, taking the mobile visualization environment to their offices.

Future Work. There are a number of areas of further work associated with the prototype, such as: investigation of user experience, usability studies with respect to BIM integration, creation of new software tools for advanced visualization functions and task specific visualization toolbox development.

Future development to include head and hand tracking is proposed, allowing for the simulation view to be updated in real-time accounting for a user's head position to fully immerse them in the simulation, as well as tracking their hand location for interaction with objects within the virtual environment. Analysis of users interaction and navigation experience will provide feedback regarding the solutions suitability. This analysis will determine how suitable the solution is for use within construction projects and how it can enhance end users productivity and experience. The mobile immersive visualization facility will be utilised to inform industrial project stakeholders of development progress and final infrastructure design choices, including; engineering review, signage, passenger movement and artwork.

\section{ACKNOWLEDGEMENTS}

The authors gratefully acknowledge funding through the EPSRC award no. EP/H02204X/1, and the inputs of industrial collaborators, including Crossrail. 


\section{REFERENCES}

Bandyopadhyay, P. K. (2004). Interlocking fastener including adhesive portions, Google Patents.

Bertol, D. (1997). Designing digital space: an architect's guide to virtual reality. New York, John Wiley \& Sons.

Black, S. (2006) "Advanced materials for aircraft interiors." High-Performance Composites URL: http://www.compositesworld.com/articles/advancedmaterials-for-aircraft-interiors.

Bouchlaghem, D., H. Shang, et al. (2005). "Visualisation in architecture, engineering and construction (AEC)." Automation in Construction 14(3): 287-295.

Brooks, F. P. (1986). Walkthrough - a dynamic graphics system for simulating virtual buildings. Workshop on Interactive 3D Graphics, University of North Carolina at Chapel Hill.

Bychinski, D. A., M. D. Lindseth, et al. (1992). Mushroom-type hook strip for a mechanical fastener, Minnesota Mining And Manufacturing Company.

Castronovo, F., D. Nikolic, et al. (2013). An Evaluation of Immersive Virtual Reality Systems for Design Reviews. ConVR. London.

Cruz-Neira, C., D. J. Sandin, et al. (1993). Surround-screen projection-based virtual reality: the design and implementation of the CAVE. 20th Annual Conference on Computer Graphics and Interactive Techniques, ACM.

Cruz-Neira, C., D. J. Sandin, et al. (1992). "The CAVE: audio visual experience automatic virtual environment." Communications of the ACM 35(6): 64-72.

Dalton, B. and M. Parfitt (2013) "Immersive Visualization of Building Information Models." DIRC Working Paper 6, version 1.0 URL: http://www.reading.ac.uk/designinnovation/for-industry/di-for-industryworking-papers.aspx.

Eastman, C., P. Teicholz, et al. (2008). BIM Handbook: A guide to building information modeling for owners, managers, designers, engineers and contractors, Wiley.

Kim, M. J., X. Wang, et al. (2013). "Virtual reality for the built environment: a critical review of recent advances." IT in Construction (IT con) 18: 279-304.

Lindkvist, C., A. Stasis, et al. (2013). Configuration management in complex engineering projects, . 2nd International Through-life Engineering Services Conference. Cranfield, UK.

Maftei, L. and C. Harty (2012). Exploring CAVEs: Using Immersive Environments for Design Work, . 28th ARCOM Annual Conference (Association of Researchers in Construction Management). Edinburgh.

Messler, R. W. (2000). "Trends in key joining technologies for the twenty-first century." Assembly Automation 20(2): 118-128.

Sacks, R., A. Perlma, et al. (2013). "Construction safety training using immersive virtual reality." Construction Management and Economics 31(9): 1005-1017.

Stasis, A., J. Whyte, et al. (2012). Building Information Modelling and Management in Infrastructure Programmes: A Scoping Study in Crossrail. Technologies for Sustainable Built Environments EngD conference. Reading.

Whyte, J. K. (2002). Virtual Reality and the Built Environment. Oxford, Architectural Press. 